\title{
Ação médico-social no caso do benzenismo em Cubatão, São Paulo: uma abordagem interdisciplinar
}

\author{
Social and medical intervention in the case \\ of benzene poisoning in Cubatão, São Paulo: \\ an interdisciplinary approach
}

Lia Giraldo da Silva Augusto 1

Tereza Carlota Pires Novaes 1

\footnotetext{
1 Departamento de Saúde Coletiva, Centro de Pesquisas Aggeu Magalhães, Fundação Oswaldo Cruz. Rua dos Coelhos 450, 1 o andar, Bairro dos Coelhos, Recife, PE, 50070-550, Brasil. giraldo@elogica.com.br
}

\begin{abstract}
Work-related health problems demand a multidisciplinary approach in which each discipline contributes its own techniques and methods, while based on a common theoretical and conceptual frame of reference. Research and intervention are based on interdependent relations between social, productive, and environmental factors. Based on experience with benzene poisoning, this review shows how the issue can be approached globally, by integrating different disciplinary processes from epidemiological and clinical research. Blood parameters altered by human exposure to benzene were studied from the perspective of hematology, integrated with the epidemiological surveillance system used as an instrument for health intervention using an interdisciplinary approach in which workers and trade unions participated throughout the program.
\end{abstract}

Key words Benzene; Occupational Exposure; Occupational Health; Social Medicine; Hematology

Resumo O tipo de problema enfrentado no campo da saúde do trabalhador exige uma abordagem integrada por diversas disciplinas com suas técnicas e métodos específicos e sustentada por um marco teórico-conceitual comum. O sistema de estudo e intervenção apresentado pelos autores foi construído através das relações entre os elementos sociais, produtivos e ambientais e considerando-os interdependentes e interdefiníveis. As autoras mostram como o processo de diferenciação disciplinar nos campos da epidemiologia e da clínica foi integrado para abordar globalmente a questão do benzenismo. As alterações hematológicas decorrentes da exposição humana ao benzeno foram estudadas dentro do marco disciplinar, integrando-se ao sistema de vigilância epidemiológica que por sua vez foi um instrumento de intervenção sanitária, num marco interdisciplinar que contou, em todo seu processo, com a participação dos trabalhadores acometidos e os sindicatos representantes das categorias afetadas.

Palavras-chave Benzeno; Exposição Ocupacional; Saúde Ocupacional; Medicina Social; Hematologia 


\section{Introdução}

A construção e adoção de um marco teóricoconceitual em saúde do trabalhador tem sido absolutamente fundamental para a intervenção nos problemas sanitários da área. A apreensão da realidade do mundo do trabalho depende das distintas visões dos pesquisadores, que podem, ou não, estarem explicitadas. No entanto, são elas que definem a abordagem, o método a ser utilizado e as novas hipóteses advindas desse processo de estudo ou de ação.

Na questão do benzenismo, colocar em jogo o duplo processo de diferenciação e integração disciplinar teve em nossa experiência os seguintes momentos distintos: identificação do problema, definição da investigação em si e do processo de negociação que foi sendo estabelecido. Esse movimento dependeu de um conhecimento que foi sendo produzido durante esse processo e que permitiu gerar novos questionamentos. Trata-se, portanto, de uma experiência na qual o sistema de estudo foi sendo construído e que a intervenção realizada foi reveladora de um grave problema sanitário que afetava amplos setores de trabalhadores dos ramos siderúrgico e petroquímico do Brasil. Podemos dizer que, entre os conflitos e dificuldades estabelecidos nessa questão, talvez o mais importante tenha sido o embate da abordagem complexa que foi introduzida, inspirada em Berlinguer (1983), Laurell \& Noriega (1989) e Garcia (1993), versus a abordagem simplificada da maioria dos profissionais de saúde de empresas e do Instituto Nacional de Previdência Social. Entendemos como visão simplificada a que se caracteriza como monocausal e que deixa de fora o contexto histórico-social do processo saúde-doença. A saúde do trabalhador está compreendida no campo da saúde coletiva e enfrenta no cotidiano de suas ações a hegemonia da tradicional medicina do trabalho. Os fundamentos epistemológicos que estão nas bases desta nova concepção foram importantes, posto que permitiram uma abordagem da complexidade dos problemas desta área.

A questão do benzenismo nos serve como um modelo para demonstrar as diferenças dos enfoques da saúde do trabalhador e da medicina do trabalho, que são distintos tanto no momento explicativo como no das práticas de prevenção.

Uma abordagem mais integrada em saúde do trabalhador surgiu na década de 60, na Europa, particularmente na Itália, instituída no seu processo de reforma sanitária e conhecida como Modelo Operário Homogêneo (Berlin- guer, 1983). As influências da experiência italiana refletiram-se na América Latina, inicialmente no México e Brasil (Laurell \& Noriega, 1989). Embora tenha havido modificações e até distorções no desenvolvimento deste modelo na América Latina, suas características auxiliaram o repensar das práticas sanitárias no mundo do trabalho, sendo as principais: 1) os trabalhadores passaram a ser sujeitos da avaliação das condições de trabalho, das reivindicações e das negociações; 2) o método de abordagem dos ambientes passou a basear-se na epidemiologia, na qual os trabalhadores, por grupos homogêneos, analisavam sua experiência de trabalho no ciclo produtivo e identificavam os riscos e danos à saúde - este processo se fundamentou na capacidade de percepção e de intervenção dos trabalhadores; 3 ) foi construído um sistema participativo de informação que adotou novos instrumentos de registro, como a carteira individual de risco e de saúde; o questionário homogêneo de risco e o mapa de risco; 4) foi estabelecido e exercitado o princípio fundamental da cidadania, caracterizado pela não delegação, isto é, a defesa da saúde não deve ser delegada aos técnicos e políticos ela cabe aos próprios trabalhadores; 5) foi estabelecido um princípio de validação qualitativa denominada validação consensual (Berlinguer, 1983). Na América Latina, o modelo foi enriquecido pela introdução do conceito de desgaste, incorporando os processos biopsíquicos na análise da dinâmica das cargas de trabalho, conforme proposto por Laurell \& Noriega (1989) e pela contribuição de Tambellini \& Câmara (1998), na construção de uma teoria para a área da saúde do trabalhador no campo da saúde coletiva, onde a questão da interdisciplinaridade aparece como a outra grande característica que a diferencia da medicina do trabalho ou da saúde ocupacional (Mendes \& Dias, 1991). A experiência brasileira tem uma forte contribuição de profissionais engajados, o que permitiu importantes avanços no conhecimento, com estudos disciplinares específicos (Lieber, 1991; Lieber \& Romano, 1997; Lacaz, 1996; Machado, 1996). Esta condição foi importante para contrapor práticas corporativas e imediatistas do mundo do trabalho. As palavras de ordem saúde não se troca por dinheiro e direito de saber foram traduzidas em instrumentos legais, pela incorporação de novas normas preventivas no ambiente e na organização do trabalho, graças ao movimento sindical e à colaboração de técnicos a ele associados (Lacaz, 1996). 


\section{História}

No final da década de 70, o sindicalismo operário paulista dava início a um processo de organização para a defesa da saúde dos trabalhadores, inspirados pelo Movimento Operário Italiano da década de 60 e pensado por um segmento de profissionais de saúde engajados no chamado Movimento Sanitário Brasileiro, que na época se agregavam em torno do recém criado Centro Brasileiro de Estudos em Saúde CEBES e no movimento de Renovação Médica de São Paulo. O documento Saúde nas Fábricas (PCB, 1978) colocava claramente uma orientação para a organização sindical de trabalhadores e para o setor saúde no sentido de construir alianças e estratégias em defesa da saúde dentro dos marcos do Modelo Operário Homogêneo italiano. E é nesse processo que se pensa a criação de uma estrutura intersindical para a saúde dos trabalhadores, que culmina, em 1980, na criação do Departamento Intersindical de Estudos em Saúde e Ambiente de Trabalho - DIESAT (Lacaz, 1996). Em São Paulo, em 1983, iniciam-se experiências de organização de atenção à saúde dos trabalhadores em algumas regiões. Uma forte demanda se verificou na Baixada Santista, vinda do Sindicato de Trabalhadores Metalúrgicos de Santos (Augusto, 1984). Essa categoria denunciava a existência de casos de intoxicações crônicas por exposição ao benzeno na indústria siderúrgica de $\mathrm{Cu}$ batão. Nessa mesma época, a Secretaria de Estado das Relações de Trabalho iniciava ações interinstitucionais para identificar problemas de exposição ao benzeno no estado. Nesse período, houve inspeções em diversas plantas industriais que produziam benzeno. Na Baixada Santista, por iniciativa do setor saúde, foi elaborado um projeto piloto que tinha como estratégia inicial a vigilância epidemiológica de agravos à saúde dos trabalhadores no parque industrial de Cubatão. Esse município era um dos mais problemáticos do Brasil em relação a poluição industrial. Até então, o sistema de vigilância epidemiológica de doenças em nosso país era restrito às doenças infecto-parasitárias.

Um sistema de informação foi construído baseado nas seguintes ações:1) notificação de problemas de saúde para algumas situações de risco, levando em consideração o perfil produtivo de Cubatão; 2) investigação epidemiológica dos casos notificados; e 3) assistência médica integral aos trabalhadores. Como fontes de notificação, foram adotados os mesmos instrumentos utilizados para as doenças infecciosas, mas também otimizou-se o boletim de inter- nação hospitalar existente na época como fonte secundária de informação e criou-se um boletim para o registro de morbidade geral dos trabalhadores através dos serviços médicos ambulatoriais das empresas.

No período de 1983 a 1995, mais de mil trabalhadores da siderúrgica do Município de $\mathrm{Cu}$ batão, São Paulo, foram afastados do trabalho por apresentarem alterações hematológicas decorrentes da exposição ambiental e ocupacional ao benzeno (FUNDACENTRO, 1981, 1988, 1993; Augusto, 1984, 1991).

As principais fontes ambientais de benzeno produzidas pelo homem incluem as emissões industriais, gases da exaustão de automóveis e abastecimento de veículos automotores (FUNDACENTRO, 1996). A partir da Segunda Guerra Mundial, o benzeno e outros hidrocarbonetos aromáticos passaram a ser obtidos do petróleo, sendo este hoje sua principal fonte, do qual se extraem frações com maior grau de pureza. Os processos carboquímicos das siderúrgicas perderam importância econômica, mas, no entanto, são os que mais preocupam do ponto de vista de contaminação ambiental. Os hidrocarbonetos aromáticos, entre eles o benzeno, são considerados subprodutos da destilação do gás de coqueria e com baixo valor comercial. Por esta razão, em geral, há pouca prioridade de manutenção das unidades de fornos de baterias de coquerias, bem como das de linhas de gás. Desta forma, a poluição ambiental no interior dessas plantas industriais é grande, sem controle e submete os trabalhadores à exposições contínuas ao benzeno (Novaes, 1992; Barbosa, 1997). O Brasil, desde 1987, é exportador deste produto e de seus derivados e tem apresentado uma curva crescente de produção, o que implica em aumento dos riscos para os trabalhadores das empresas produtoras (FUNDACENTRO, 1981, 1988, 1993). Conforme dados da Associação Brasileira de Indústria Química (ABIQUIM, 1990), 5\% da produção brasileira é consumida na indústria do álcool, para fabricação do álcool anidro, e 95\% são consumidos pelas indústrias químicas e petroquímicas. Assim, para a realidade brasileira, podemos dizer que a exposição ao benzeno é um grave problema de saúde pública.

\section{Objetivo}

Evidenciar como a implantação de um sistema de informação epidemiológica participativa em saúde do trabalhador, a partir do entendimento da complexidade do problema em questão, permitiu investigar as alterações hemato- 
lógicas em trabalhadores expostos ao benzeno e propor ações de proteção à saúde no campo médico-social.

\section{Abordagem}

A identificação de grande número de casos de benzenismo em Cubatão foi uma importante revelação técnico-científica, principalmente no contexto sócio-ambiental desse município. Até a década de 80, a intensa poluição industrial nessa região era estudada estritamente do ponto de vista do ambiente físico (contaminação hídrica e atmosférica, impactos geológicos e ecológicos), enquanto a saúde, quando muito, apenas era tangencial ou seus estudos não tinham a continuidade e os aprofundamentos necessários. No processo de conscientização dos trabalhadores pela defesa da saúde, os aspectos epidemiológicos e clínicos do benzenismo ganharam importância nacional e foram fundamentais para a implementação de ações preventivas. As principais características da questão sanitária do benzeno e que favoreceram esse processo foram as seguintes: 1) tratarse de uma substância química de largo uso industrial; 2) ter grande importância econômica, por apresentar um forte parque industrial produtivo e consumidor no Brasil, que nessa época já era exportador desse produto; 3 ) ser uma substância sabidamente carcinogênica, mas até então não reconhecida pela legislação brasileira; e 4) expor grandes contingentes humanos nos ambientes de trabalho.

Inicialmente surgiram alguns conflitos na caracterização do problema do ponto de vista epidemiológico e ambiental no estabelecimento de relação causal com o processo produtivo, no diagnóstico clínico, na vigilância em saúde, no monitoramento ambiental e biológico, e, por fim, na cobertura previdenciária (Augusto, 1991; Novaes, 1992).

O enfrentamento de cada uma destas questões exigiu buscar um duplo processo de diferenciação e integração disciplinar referenciado à totalidade do problema.

Foi nesse cenário que se teve de estudar com profundidade o sistema hematopoiético de produção de células sangüíneas, as razões ambientais da extensa exposição humana ao benzeno na siderúrgica (COSIPA, 1981; Ruiz, 1989; Augusto, 1991), bem como o processo produtivo do benzeno no Brasil e suas relações econômico-produtivas (Novaes, 1992). Para tais estudos foram aderindo pesquisadores de diferentes especialidades (médicos sanitaristas e do trabalho, clínicos hematologistas, epide- miologistas, químicos analíticos, bioquímicos, engenheiros de produção e de segurança).

A construção de um modelo explicativo integrado deu-se através de intensa prática interdisciplinar. Com a extensão da identificação do benzenismo em outros pólos industriais do país (São Paulo, Bahia, Rio de Janeiro, Minas Gerais, Espírito Santo e Rio Grande do Sul) e das reivindicações dos trabalhadores daí derivadas por melhoria nas condições de trabalho e pelo reconhecimento do dano à saúde, houve um verdadeiro embate teórico-conceitual e jurídico para o estabelecimento de medidas normativas. No processo de negociação, se instalou, desde o princípio, a ação interdisciplinar, cujas práticas levaram à necessidade de atualização de conhecimentos. Prioridades foram emergindo desse processo. A primeira grande síntese surge no nível jurídico pela publicação da Norma do Benzeno pelo Governo do Estado de São Paulo, resultado do trabalho de uma comissão interinstitucional, que trabalhou um ano em sua elaboração, seguido de dois seminários para apreciação das propostas. Foi um processo negociado e aberto, que atualizou os procedimentos normativos no âmbito da saúde, ambiente, trabalho e previdência social. Esse trabalho interinstitucional e interdisciplinar repercutiu em nível nacional, levando, em 1994, o então Ministério da Previdência Social a reproduzir quase integralmente a Norma do Estado de São Paulo no âmbito Federal. No entanto, as gritantes diferenças regionais, tanto de mobilização social dos trabalhadores como tecnológica-empresariais e político-jurídicas, geraram um movimento político de reação às importantes conquistas na experiência paulista, refletidas na Norma da Secretaria de Estado da Saúde de São Paulo. Esse contra-movimento atuou organizadamente no sentido de recolocar novamente os interesses econômicos como diretores hierárquicos do processo. No final do ano de 1995, criou-se a Comissão Nacional Permanente do Benzeno-CNP-B. Essa comissão, fundada sobre o princípio do tripartismo, retorna metodologicamente à concepção clássica das questões de saúde, sob o ângulo da Organização Internacional do Trabalho - OIT, com comissões onde o processo de indicação de composição foi muito mais fechado e com mecanismos de exclusão de membros nomeados, que dispensaram explicações. Esse processo continuou no ano de 1996, e verificou-se uma grande fragilização nas ações interinstitucionais e na questão conceitual, fazendo com que os indicadores biológicos de efeito perdessem novamente terreno para os indicadores de exposição, tanto ambientais como em fluidos 
biológicos. Conceitualmente, coloca-se o tripartismo como substituto mais restrito do interdisciplinar. Esse processo vem acompanhado de retrocessos político-institucionais mais amplos nas áreas trabalhistas e providenciárias e reflete orientações políticas nacionais e internacionais que hierarquizam o aspecto econômico como diretor das questões de saúde (FUNDACENTRO, 1996).

Limitando-nos aos acontecimentos localizados na siderúrgica de Cubatão, o que podemos verificar é que o sistema econômico-produtivo, a assistência médico-previdenciária e o próprio sistema fisiológico de produção sangüínea são subsistemas de sistemas complexos que constituem a saúde dos trabalhadores expostos ao benzeno. A compreensão das relações entre esses elementos foi o que possibilitou, de maneira dinâmica, imprimir uma abordagem integral para esta questão. A saúde por nós entendida tem uma dimensão transdisciplinar e não pode estar subordinada à níveis de complexidade inferior, como, por exemplo, era tradicional se fazer em relação ao diagnóstico de benzenismo, absolutamente dependente do chamado Limite de Tolerância Ambiental, baseado na análise quantitativa de benzeno no ar por períodos de trabalho ou do Limite Biológico de Exposição, aferido pela dosagem de fenol na urina dos expostos, abordagem esta que denominamos de simplificada ou reducionista (Augusto, 1991; Novaes, 1992).

Ainda do ponto de vista metodológico, além das características já apontadas para a abordagem da saúde do trabalhador (trabalhador como sujeito), outra importante característica foi a superação do modelo clínico-individual pelo clínico-epidemiológico, considerando-se o contexto sócio-econômico e político em que ocorrem os processos que determinam o binômio saúde-doença. Denominamos esta abordagem de complexa e interdisciplinar.

\section{Resultados e discussão}

As avaliações histocitológica da medula óssea, realizadas em trabalhadores portadores de alterações hematológicas secundária a exposição ao benzeno (Ruiz, 1989; Ruiz et al., 1991; Augusto, 1991; Augusto et al., 1993), permitiram colocar em evidência os mecanismos de intoxicação e de compensação fisiológica do sistema hematopoiético, seus limites e expressões clínicas.

No início da identificação dos casos de benzenismo, todo o esforço diagnóstico foi concentrado nas alterações observadas na conta- gem global e diferenciada de células do sangue periférico. Entre as alterações observadas, a neutropenia - diminuição de neutrófilos - era a mais relatada, embora, com freqüência, observavam-se também alterações qualitativas em plaquetas e eritrócitos. A neutropenia era praticamente a alteração responsável pela diminuição da contagem global dos leucócitosleucopenia (Augusto, 1984). Estas alterações passaram a representar um sinal de alerta da intoxicação entre os expostos e eram observadas facilmente em hemogramas. Os hemogramas, na época, já eram realizados com métodos de contagem automatizada por boa parte dos laboratórios de apoio diagnóstico. A utilização dessa característica clínica, de observação quantitativa, foi fundamental para estabelecer-se um controle social do efeito orgânico da exposição humana ao benzeno na siderúrgica de Cubatão, São Paulo. Nessa época, havia um deliberado ocultamento, pela empresa, dos danos ocorridos na saúde dos trabalhadores expostos.

Embora a intoxicação pelo benzeno seja uma síndrome complexa que envolva aspectos quantitativo e qualitativos da função de diversos órgãos e sistemas (sistema sangüíneo, nervoso central e periférico, imunológico, reprodutor, citogenético e endocrinológico), havia dificuldade para caracterização médico-previdenciária do dano ocupacional em função dos conflitos político-econômicos existentes. Estes conflitos se expressaram com maior intensidade em decorrência da abrangência epidemiológica do problema, com centenas de trabalhadores acometidos. Inicialmente, o diagnóstico ficou circunscrito às alterações quantitativas observadas no sangue periférico. O reconhecimento dessas alterações como acidente do trabalho foi um avanço, pois, até então, a única manifestação nosológica passível de nexo com o benzeno era a anemia aplástica. Mesmo sabedores do efeito leucemogênico do benzeno, os casos de leucemia em expostos regulares a esse agente químico dificilmente tinham o reconhecimento do nexo causal. Então, buscouse identificar sinais de dano à saúde que fossem precoces e, de preferência, reversíveis. Neste sentido, quando foram observadas as alterações periféricas do sangue em expostos, acreditou-se tratar-se de um evento pré-clínico, e sua valorização permitiu, pela primeira vez, que a previdência social se responsabilizasse pela seguridade desses trabalhadores. Assim, passou a haver reconhecimento destas alterações como danos à saúde, caracterizando-as como agravo à saúde decorrente do trabalho. 
Para essa caracterização, um diagnóstico diferencial com outras patologias e o aspecto temporal da evolução do perfil hematimétrico foram importantes. A análise da série histórica dos hemogramas foi um procedimento incorporado à prática médica no controle dos indivíduos expostos e dos que apresentavam alterações, vindo a constituir-se como indicador de dano à saúde decorrente da exposição ao benzeno. Assim, o caráter meramente quantitativo de diagnóstico foi ganhando complexidade.

Nesse processo, foi interessante a construção do conceito de hipersensibilidade e de susceptibilidade individual diante da exposição ambiental ao benzeno. Pela primeira vez, o Instituto Nacional de Previdência Social passou a considerar um dano celular quantitativo, devido às causas ambientais, como incapacitante para o trabalho. Tal reconhecimento foi um importante conceito incorporado oficialmente à prática pericial e de reabilitação profissional. Não se tratava mais de valorização apenas da perda de função físico-sensorial para o desempenho da atividade normal de trabalho, mas também o impedimento para o trabalhador continuar sua atividade em ambiente de risco para exposição ao benzeno. Neste momento, um grande debate foi instituído para discutir o significado de risco.

Esta hipótese da leucopenia/neutropenia como sinal precoce de intoxicação exigiu estudos no nível central (medula óssea) dos indivíduos acometidos. Era fundamental compreender a fisiologia da hematopoiese. Os resultados obtidos refutaram a hipótese inicial, pois, ao contrário do que se acreditava, revelaram que o dano central, em alguns casos, era mais expressivo do que as alterações periféricas observadas no hemograma (Ruiz, 1989; Augusto, 1991).

O estudo histocitológico da medula óssea, portanto, de caráter absolutamente disciplinar, permitiu demonstrar a evidência de que há uma grande reserva funcional da medula óssea, que permite um processo de compensação fisiológica de caráter homeostático da hematopoiese. Esta evidência passou a sustentar a posição de valorização ainda maior das alterações periféricas, mesmo as de pequena extensão. Na absoluta maioria, os casos que tiveram um diagnóstico diferencial bem elaborado para leuco-neutropenia, ao se realizar a análise histocitológica da medula óssea, apresentaram correspondência entre o quadro periférico e o central (Ruiz, 1989; Augusto, 1991). Para a maioria destes casos, a medula óssea revelava um quadro de diminuição global de células, com preponderância na diminuição da série granulocítica. Neste sentido, na literatura en- contramos modelos explicativos para a não observação freqüente de anemia e plaquetopenia em nível periférico, apesar das alterações na medula óssea poderem atingir as três séries sangüíneas (Snyder et al., 1987). Parece que os mecanismos fisiológicos de compensação da queda de células centrais precursoras de hemácias e plaquetas são mais eficazes do que os da série granulocítica. Talvez seja pelo fato desta última compor um sistema mais complexo e de haver mais alternativas fisiológicas para manutenção da homeostase imunológica.

O embate conceitual sobre a normalidade hematimétrica foi acirrado pelos interesses econômicos em jogo. Mesmo diante de evidências irrefutáveis da hematotoxicidade do benzeno e do grave descontrole ambiental no interior da siderúrgica (COSIPA, 1981), setores médicos ligados à empresa insistiam na tese de que o problema das alterações sangüíneas era decorrente de um fator étnico/regional que determinava um padrão de normalidade hematimétrica diferente, com menor número de leucócitos/neutrófilos. Isto é, esses representantes levantaram a hipótese de que a diminuição de leucócitos e neutrófilos na maioria dos casos estava ligado à raça negra e ao fator regional, principalmente em regiões com alta prevalência de endemias, de onde procediam a maioria dos trabalhadores expostos, isto é, de Minas Gerais e do Nordeste (Bento \& Augusto, 1997). Estes argumentos colocados pelos setores médico-empresariais criaram mais confusão do que esclarecimentos no equacionamento do problema. No entanto, este argumento serviu aos propósitos das empresas e de setores da previdência social, no sentido de buscarem continuamente a descaracterização do problema de saúde nos ambientes produtivos onde o benzeno se faz presente, ao invés de buscar sanear os ambientes e controlar os riscos.

Também foi estudado por Augusto (1991) a evolução do quadro hematimétrico dos intoxicados após o afastamento do trabalho, uma coorte de 61 trabalhadores avaliados num período de seis anos. Observou que a normalidade hematimétrica se estabelecia com um tempo mediano de cinco anos de afastamento da área de risco. Isto significava que, para $50 \%$ dos casos, as alterações permaneciam além desse tempo (Augusto, 1991; Augusto et al., 1993). Esta normalidade foi entendida como uma compensação fisiológica e não como uma capacidade de regeneração das células progenitoras e precursoras do sistema hematopoiético (steamcells). No seguimento clínico desses pacientes, foi possível analisar os resultados das análises histológicas de medulas ósseas de trabalhado- 
res que, embora tivessem normalizado o leucograma, mantiveram um quadro de granulocitopenia central. Estes achados auxiliaram o processo de normatização dos procedimentos previdenciários e periciais.

Esta normas foram importantes para inibir os procedimentos de alta médico-pericial com base apenas no simples retorno da hematimetria aos padrões convencionados de normalidade. Assim, um outro entendimento do prognóstico para os casos em seguimento foi construído.

Os trabalhadores expostos ao benzeno com alterações hematológicas compatíveis com a intoxicação benzênica e que não apresentavam outras patologias explicativas do quadro passaram a ser considerados hipersusceptíveis compensados, não podendo retornar à atividade de trabalho em ambiente de risco (INAMPS, 1987; INSS, 1987).

A incorporação deste conceito foi fundamental para interpretar as variações clínicas observadas e oferecer proteção aos já intoxicados frente ao risco de novas exposições ocupacionais pela alta médico-pericial.

Desta forma, mesmo sabedores do caráter restritivo do hemograma, a estratégia adotada pelo Programa de Vigilância Epidemiológica da Secretaria Estadual de Saúde de São Paulo de considerar as alterações hematológicas como parâmetros de identificação dos casos de benzenismo e a leucopenia/neutropenia como sinal sentinela da intoxicação benzênica mostrou-se correta.

Essa orientação permitiu avaliar a extensão do dano da exposição ambiental no interior da empresa, identificar as situações de risco, estabelecer critérios para controle médico periódico dos grupos expostos, bem como para o diagnóstico e seguimento dos casos de benzenismo. Esse sinal foi utilizado como um marcador para análise da série histórica do hemograma que era recomendada como um instrumento para o monitoramento biológico de efeito da exposição (Wakamatsu \& Fernicola, 1980).

Nosso entendimento inicial era de que a leucopenia/neutropenia era um sinal precoce da intoxicação, mas, como vimos acima, esta evidência não se confirmou pelos estudos histocitológicos da medula óssea.

No entanto, estes critérios trouxeram algumas complicações, pois, uma vez mais, os médicos do trabalho e peritos reduziam todo o diagnóstico apenas aos sinais quantitativos da série leucocitária, desconsiderando o caráter sindrômico do benzenismo.

A complexização do diagnóstico nunca foi enfrentada pelo setor médico, e, por outro la- do, interessava aos trabalhadores um sinal clínico de fácil interpretação que desnudasse o problema e o tirasse do exclusivo poder do médico do trabalho, permitindo, assim, uma ação coletiva. Mas, por outro lado, a simplificação do diagnóstico deu oportunidade ao setor empresarial de buscar a descaracterização do quadro clínico do benzenismo. Além disto, também os laboratórios de análises clínicas ganharam notoriedade com a realização massiva de exames hematológicos, tornando-se um fato para o aumento de suas receitas nas regiões onde o conflito existia. Convites aos patologistas para discutir os parâmetros de normalidade hematimétrica foram freqüentes. Um seminário apoiado pelo Serviço Social da IndústriaSESI, realizado no Município de São Roque, São Paulo, em 1987, promovido pela Sociedade Brasileira de Hematologia e Hemoterapia e pelo Colégio Brasileiro de Hematologia, foi realizado com o objetivo extrínseco de sugerir mudanças nos parâmetros de normalidade (Mendes, 1987). A presença de pesquisadores e de sanitaristas nesse evento promoveu um debate aprofundado da questão e recomendações foram tiradas para o equacionamento do problema sem ocultar sua gravidade. Os profissionais compromissados com os empresários, inconformados, realizaram um segundo encontro na Associação Paulista de Medicina, em 1993, na tentativa de, mais uma vez, questionar os critérios de diagnóstico do benzenismo instituídos pelos órgãos públicos no nível da Previdência Social, do Trabalho e da Saúde. Nessa época, já entendíamos que, além de manter a avaliação hematológica como nuclear na identificação de casos de benzenismo, era preciso acrescer a avaliação dos danos neuropsicológicos, imunológicos e citogenéticos. Estas análises até agora foram pouco exploradas e certamente fazem falta para identificar outras dimensões dos elementos bio-sócio-ambientais do benzenismo.

Outro aspecto conflitante já citado foi o relativo à legislação brasileira, que admitia um limite de tolerância para o benzeno de 8 ppm (partes por milhão) para 48 horas de trabalho semanal (Ministério de Trabalho, 1994). Esta legislação resultou num modelo simplista baseado na avaliação ambiental por métodos unicamente quantitativos de análise química (Lieber, 1991; Novaes, 1992). As recomendações internacionais desde 1976 (OSHA, 1987) já eram no sentido da redução drástica desses limites para 1 ppm e, até mesmo, de sua supressão. Esta proposição se dá em razão do benzeno ser cancerígeno para o homem (IARC, 1982). Para nós, que estudávamos com profundidade o problema, estava claro que a saúde não pode- 
ria ficar subordinada aos limites burocráticos de exposição ao benzeno.

Neste sentido, a legislação brasileira de medicina do trabalho é ainda sustentada pelo chamado modelo de fatores de risco que, nos casos de riscos químicos, se apoia nos limites de exposição ambiental e biológico, definido em estudos toxicológicos experimentais (Wakamatsu \& Fernicola, 1980).

Este modelo não leva em consideração a superposição de diversos fatores ambientais presentes nos processos de trabalho, os aspectos da organização do trabalho, a variabilidade biológica, a susceptibilidade individual e nem outros fatores nosológicos preexistentes.

O modelo de avaliação ambiental suportado por avaliações quantitativas isoladas começaram a ser colocadas em cheque em 1982 por técnicos da Fundação Jorge Duprat Figueiredo de Segurança e Medicina do Trabalho (FUNDACENTRO), a propósito da questão do benzeno. Esta nova proposição evoluiu até 1993, quando houve a elaboração de um dispositivo normativo da vigilância sanitária de São Paulo, que foi fonte inspiradora de outros instrumentos reguladores criados em nível federal (Novaes, 1992; FUNDACENTRO, 1981, 1988, 1993; Secretaria de Estado da Saúde de São Paulo, 1993).

Ao ser reconhecido o efeito cancerígeno do benzeno, retirou-se a possibilidade de se estabelecer um limite de exposição tolerável. As exposições deixaram de ser apenas uma questão de saúde, passando para uma questão de direito dos trabalhadores de conseguirem (ou não) evitar os danos decorrentes do trabalho. Assim, deixou-se de outorgar para uma única avaliação técnica, de âmbito químico-analítico, a palavra final sobre a saúde do indivíduo.

O estudo pioneiro iniciado em Cubatão, como vimos, ganhou dimensão política em toda parte do território nacional onde o benzeno seja produzido ou utilizado. Neste processo, a forte mobilização sindical e técnica permitiu, em 1995, a organização de uma comissão tripartite nacional da qual participam três bancadas: governamental, representante dos trabalhadores e representantes dos empresários. Os esforços estão concentrados na elaboração de normas técnicas e de procedimentos de gerenciamento de risco da exposição ao benzeno, focalizando a ação de vigilância no local de origem (Machado, 1996).

Conforme dados de 1993 (FUNDACENTRO, 1995), nas indústrias que empregam benzeno no país, há cerca de 58.447 trabalhadores diretos e 116.635 trabalhadores de empreiteiras, sendo 35.634 diretamente expostos a esse produto em sua atividade de trabalho. Ainda não foram realizados levantamentos de estimativa de populações vizinhas a essas fontes de emissões de benzeno e que estariam também expostas. Entre os estados que concentram a maior parte das indústrias que produzem ou utilizam benzeno estão Rio Grande do Sul, São Paulo, Rio de Janeiro, Minas Gerais, Espírito Santo e Bahia.

Atualmente, os casos de benzenismo e a situação dos ambientes de trabalho da Companhia Siderúrgica Paulista estão sendo estudados por Costa (1996). Este autor, em 1996, avaliou uma série histórica dos hemogramas de 328 trabalhadores dessa empresa, numa série histórica de 5 anos, e encontrou uma incidência de 46,95\% de alterações hematológicas, sendo que destas, 15,85\% mantém alterações persistentes. Este é um dado que indica a persistência do problema de exposição ambiental ao benzeno na empresa, apesar de todos os anos de luta e tentativas de solução deste problema.

\section{Conclusões}

A articulação dos estudos e ações na questão do benzenismo se deu, como vimos, dentro de um intenso processo de participação social, o que garantiu a integração do conhecimento disciplinar dentro de uma abordagem global do problema, sustentado por um conceito mais amplo de saúde, que tem um forte aspecto teórico-conceitual e que tem suas bases operativas-materiais de inserção na chamada saúde do trabalhador, em contraponto à abordagem e práticas da medicina do trabalho. Foi possível expressar em instrumentos legais normativos um modelo de prevenção que não aceita $a$ priori qualquer nível de exposição ao benzeno por reconhecê-lo como substância cancerígena, bem como foi possível, nesse problema, apresentar propostas para superação do modelo de subordinação da saúde aos níveis inorgânicos, restabelecendo, assim, os níveis hierárquicos da sua natureza bio-social e reconhecendo o caráter complexo de todo esse sistema.

De um nível de simples formulação de critérios para o diagnóstico e de análise ambiental, partiu-se para outros mais complexos que incorporaram o cenário tecnológico e econômico da produção e consumo do benzeno. Das avaliações celulares morfológicas, caminhouse para um aspecto mais funcional do sangue, assim como das análises quantitativas para formulação de métodos qualitativos de controle. A evolução histórica da legislação, recuperada nesse processo, foi fundamental para os avanços das normas de vigilância em saúde 
propostos (Novaes, 1992). Tais enfoques foram sendo construídos ao longo de um período de 12 anos, no qual mais de três mil casos de benzenismo foram registrados no Brasil. Podemos dizer que os trabalhadores intoxicados percorreram com os pesquisadores este caminho, e sua contribuição foi de conhecimento profundo das atividades e do ambiente de trabalho. Esta é uma outra característica da abordagem em saúde do trabalhador: o reconhecimento do saber operário que, aliado ao saber científico, confere ao conhecimento dele gerado a força de transformação, que é o objetivo maior que damos à ciência. Concordamos com Lieber \& Romano, quando afirmam que "a melhoria das condições de trabalho passa necessariamente por diferentes formas de compreensão da condição humana, nos iluminando o desejável e nos dirigindo na busca do possível" (Lieber \& Romano, 1997:27).

\section{Referências}

ABIQUIM (Associação Brasileira da Indústria Química), 1990. Anuário da Indústria Química Brasileira-1990. São Paulo: ABIQUIM.

AUGUSTO, L. G. S., 1984. Benzolismo em uma siderúrgica. Revista de Saúde Ocupacional e Segurança-SOS, 10:153-187.

AUGUSTO, L. G. S., 1991. Estudo Longitudinal e Morfológico (Medula Óssea) em Pacientes com Neutropenia Secundária à Exposição Ocupacional e Crônica ao Benzeno. Dissertação de Mestrado, Campinas: Departamento de Clínica Médica, Faculdade de Ciências Médicas, Universidade Estadual de Campinas.

AUGUSTO, L. G. S.; VIGORITTO, A. C. \& SOUZA, C. A., 1993. Alterações histológicas de medula óssea secundária à exposição ao benzeno e a evolução hematológica do sangue periférico em pacientes acometidos. Revista Brasileira de Saúde Ocupacional, 21:85-92.

BARBOSA, E. M., 1997. Exposição Ocupacional ao Benzeno: O Ácido Trans-Trans-Mucônico como Indicador Biológico de Exposição na Indústria do Refino do Petróleo. Dissertação de Mestrado, Rio de Janeiro: Escola Nacional de Saúde Pública, Fundação Oswaldo Cruz.

BENTO, M. A. S. \& AUGUSTO, L. G. S., 1997. Insalubridade no Trabalho, Meio Ambiente e Raça: $\mathrm{O} C \mathrm{Ca}$ so dos Trabalhadores das Siderúrgicas. São Paulo: Editora do Centro de Estudos das Relações do Trabalho e Desigualdades.

BERLINGUER, G., 1983. A Saúde nas Fábricas. São Paulo: Editora Cebes/Editora Hucitec/Editora Oboré.

COSTA, D., 1996. Relatório da Análise de Hemogramas dos Trabalhadores da Coqueria e Carboquímicos da COSIPA. São Paulo: Ministério do Trabalho. (mimeo.)
COSIPA (Companhia Siderúrgica Paulista), 1981. Estudo sobre a Leucopenia. São Paulo: Gomes Editora e Consultoria Empresarial.

DUVAL, B. G., 1993. Investigación disciplinaria y enfoque sistémico. Avance y Perspectiva, 12:67-75.

FUNDACENTRO (Fundação Jorge Duprat Figueiredo de Segurança e Medicina do Trabalho), 1981. Laudo Técnico de Avaliação de Áreas Insalubres da COSIPA - Volume da Coqueria. São Paulo: FUNDACENTRO. (mimeo.)

FUNDACENTRO (Fundação Jorge Duprat Figueiredo de Segurança e Medicina do Trabalho), 1988. Proposta para a organização de estruturas de controle de exposição ao benzeno: Competências e responsabilidade Atualidades em Prevenção de Acidentes, 19:7-10.

FUNDACENTRO (Fundação Jorge Duprat Figueiredo de Segurança e Medicina do Trabalho), 1993. Benzeno - Subsídios Técnicos à Secretaria e Segurança e Saúde no Trabalho. São Paulo: FUNDACENTRO/ Ministério do Trabalho.

FUNDACENTRO (Fundação Jorge Duprat Figueiredo de Segurança e Medicina do Trabalho), 1995. Benzeno - Subsídios Técnicos à Secretaria de Segurança e Saúde no Trabalho. São Paulo: FUNDACENTRO/Ministério do Trabalho.

FUNDACENTRO (Fundação Jorge Duprat Figueiredo de Segurança e Medicina do Trabalho), 1996. Acordo e Legislação sobre Benzeno. São Paulo: FUNDACENTRO/Ministério do Trabalho.

GARCIA, R., 1986. Los Problemas del Conocimiento y la Perspectiva Ambiental del Desarrollo. México: Editorial Siglo XXI.

IARC (International Association for Research in Cancer), 1982. Benzene. Monographs on the Avaliation of Carcinogenic Risk of Chemicals to $\mathrm{Hu}$ man, 29. Lyon: IARC. 
INAMPS (Instituto Nacional de Previdência Social), 1987. Circular 297. São Paulo: INAMPS. (mimeo.)

INSS (Instituto Nacional de Seguridade Social), 1987. Circular 03. São Paulo: INSS. (mimeo.)

LACAZ, F. A. C., 1996. Saúde do Trabalhador: Um Estudo sobre as Formações Discursivas da Academia, dos Serviços e do Movimento Sindical. Tese de Doutorado, Campinas: Faculdade de Ciências Médicas, Universidade Estadual de Campinas.

LAURELl, A. C. \& NORIEGA, M., 1989. Processo de Produção e Trabalho: Trabalho e Desgaste Operário. São Paulo: Editora Hucitec.

LIEBER, R. R., 1991. Trabalho em Turnos e Riscos Químicos: O Horário de Trabalho como Fator Interveniente no Efeito Tóxico. Dissertação de Mestrado, São Paulo: Departamento de Saúde Ambiental, Faculdade de Saúde Pública, Universidade de São Paulo.

LIEBER, R. R. \& ROMANO, N. S., 1997. Saúde, ambiente, produção e o enfoque de risco. In: Anais do 5o Encontro Nacional de Estudos do Trabalho, p. 27. Rio de Janeiro: Associação Brasileira de Estudos do Trabalho - ABET.

MACHADO, J. M. H., 1996. A Heterogeneidade da Intervenção: Alternativas de Vigilância em Saúde do Trabalhador. Tese de Doutorado, Rio de Janeiro: Escola Nacional de Saúde Pública, Fundação Oswaldo Cruz.

MENDES, R. \& DIAS, E. C., 1991. Da medicina do trabalho à saúde do trabalhador. Revista de Saúde Pública, 25:341-349.

MENDES, R., 1987. Benzenismo - Subsídios para a identificação de grupos ocupacionais de mais elevado risco de exposição. Boletim da Sociedade Brasileira de Hematologia e Hemoterapia, 98:135147.

MINISTÉRIO DO TRABALHO, 1994. Artigo 3o da Portaria SSST no 03, de 10/03/94. In: Legislação em Segurança e Saúde no Trabalho (Ministério do Trabalho, org.), Vol. 1, pp. 99-104, Brasília: Ministério do Trabalho.

NOVAES, T. C. P., 1992. Bases Metodológicas para Abordagem da Exposição ao Benzeno. Dissertação de Mestrado, São Paulo: Instituto de Química, Universidade de São Paulo.
PCB (Partido Comunista Brasileiro), 1978. Saúde nas Fábricas. Documento Interno de Orientação. São Paulo: PCB. (mimeo.)

OSHA (Occupational Safety and Health Administration), 1987. Occupational Exposure to Benzene. Proposed rule and notice of hearing. Washington, D.C.: U.S. Department of Labor, Occupattional Safety and health Administration.

RUIZ, M. A., 1989. Estudo Morfológico de Medula Óssea em Pacientes Neutropênicos da Industria Siderúrgica de Cubatão. Tese de Doutorado, São Paulo: Departamento de Clínica Médica, Faculdade de Ciências Médicas, Universidade Estadual de Campinas.

RUIZ, M. A.; VASSALO, J. \& SOUZA, C. A., 1991. Morphologic study of the metalurgical industrial of Cubatão, São Paulo, Brazil. Journal of Occupational Medicine, 33:81-83.

SECRETARIA DE ESTADO DA SAÚDE DE SÃO PAULO, 1984. Resolução 69, de 2/10/1984. Institui a notificação de agravos à saúde decorrentes do trabalho no município de Cubatão. São Paulo: Diário Oficial do Estado, Vol. 2 (Saúde), Seção I, p. 96, $4 / 10 / 1984$.

SECRETARIA DE ESTADO DA SAÚDE DE SÃO PAULO, 1993. Resolução 184, de 6/6/1984. Norma técnica referente ao diagnóstico da intoxicação e controle da exposição ocupacional ao benzeno. São Paulo: Diário Oficial do Estado, Vol. 2 (Saúde), Seção I, p. 107, 9/6/1993.

SNYDER, R.; JOWA, I.; WITZ, G.; KALF, G. \& RUSHMORE, T., 1987. Formation of reactive metabolites from benzene. Archives of Toxicology, 60:6164 .

TAMBELLINI, A. T. \& CÂMARA, V. M., 1998. A temática saúde e ambiente no processo de desenvolvimento do campo da saúde coletiva: Aspectos históricos, conceituais e metodológicos. Ciência \& Saúde Coletiva, 3:47-59.

WAKAMATSU, C. L. \& FERNICOLA, N. A. G. G., 1980. Intoxicação profissional por benzeno. In: Medicina do Trabalho/Doenças Ocupacionais (R. Mendes, org.), pp. 479-486, São Paulo: Sarvier. 